\title{
Distance Delivery of the MS HP Degree at Georgia Tech
}

\author{
Heather J. Gepford, Nolan E. Hertel \\ Georgia Institute of Technology
}

The Center for Distance Learning (CDL) at Georgia Institute of Technology has been delivering high-quality, graduate level courses in engineering to off-campus students since 1977. Currently offered courses can be applied towards a master's degree in Electrical/Computer Engineering, Environmental Engineering, Industrial Engineering, Mechanical Engineering, and Health Physics. The video MSHP program has been available to students since 1984. In recent years, options for off-campus students have expanded to include web-based delivery of courses in Mechanical Engineering, Electrical Engineering, and Environmental Engineering.

\section{Video Program Logistics}

Two registration options are available to distance learning students. The first, Registered Graduate Option (RGO), is for students who have been formally admitted to Georgia Tech's Graduate School. Students in the RGO option meet the same admission requirements as any Georgia Tech graduate student. When taking classes, the RGO student completes the same assignments and exams as campus students. Grades earned are recorded by the Registrar, becoming a permanent part of the student's Georgia Tech academic record. A faculty advisor is assigned to assist with program planning and special problems.

The Professional Development Option (PDO), on the other hand, is designed for students who desire to enhance their knowledge of a particular subject. Students registered in the PDO do not receive academic credit for completion of the course, even if subsequently admitted to the graduate program. When registering, the student indicates if they wish to take the course with or without a grade assigned. Students taking the course without a grade need not turn in homework or take exams. Those taking the course for a grade must complete all assignments and exams. Grades are sent to the student, but do not appear on a Georgia Tech transcript. In addition, a letter indicating the Continuing Education Units earned will be issued to the PDO student upon request.

The Center for Distance Learning is responsible for administration of the video program, serving as a point of contact for all logistical coordination. Course registration, through the CDL, takes place over the web, by fax, or by mail. Course listings are available online approximately two months prior to the beginning of each term. Required textbooks can be ordered from the Georgia Tech Bookstore using an order form available at the CDL's website. Video students are limited to two courses per term. 
Staff from the CDL is responsible for recording instructor presentations and student/instructor interactions during regular Georgia Tech classes. Each lecture is delivered to the student on videotape, arriving within three days of the lecture date. In some instances, courses have been delivered by live two-way video to campus by faculty at other locations. As with GT faculty taught courses, these course transmissions are taped and distributed to distance learning students enrolled in the class. All tapes must be returned to the CDL within four weeks of receipt.

Enclosed with a video package the student will find any class handouts or homework assignments distributed to campus students during the lecture. The due date for homework assignments and projects is two weeks after the due date for campus students, unless otherwise indicated by the professor. Assignments are returned to the CDL by fax; the CDL forwards the work to the professor for grading.

Tests and exams must be taken exactly two weeks after administration to campus students. At each off-campus location, a proctor must be identified and approved by CDL to administer examinations. If a suitable proctor is not available at the student's place of employment, arrangements can be made to have exams administered by a local college or library.

Examinations will be mailed to the proctor, who must sign a cover page indicating the exam was administered as specified in the accompanying directions. The proctor returns the completed exam to CDL by fax or mail.

Laboratory courses must also be taken by distance learning students. The laboratory portion of the class is handled in one of two ways: the students travel to the campus to perform labs on two or three intense weekends or, if they live near appropriate facilities, they may be able to complete all the experiments at their home location.

Although the CDL plays a pivotal role in the video MSHP program, the course instructor is accessible to the student. Contact may be made directly with the instructor or other faculty members by telephone, e-mail, and fax.

\section{MSHP Specifics}

At Georgia Tech, the NRE/HP program is housed within the George W. Woodruff School of Mechanical Engineering. The Woodruff School's master's program in health physics has in recent years produced approximately 15 percent of the nation's MSHP degrees. The distance delivery of the MSHP is a major component of the continued strength and size of the program.

Students enrolled in the distance learning program under the Registered Graduate Option take the same classes and meet the same graduation requirements as campus MSHP students. As with campus students, RGO students must maintain a 3.0 grade point average. Thirty credit hours are required to obtain the degree; a thesis is not required. The degree earned by the video student is the same as the degree earned by those who attend classes on campus. 
The MSHP has the minimum course credit requirements as indicated in the following tables.

Master of Science in Health Physics Degree Requirements

\begin{tabular}{lcc} 
Course Requirements & $\begin{array}{c}\text { Without Thesis } \\
\text { (Semester Hours) }\end{array}$ & $\begin{array}{c}\text { With Thesis } \\
\text { (Semester Hours) }\end{array}$ \\
\hline Required Health Physics Courses: & 12 & 12 \\
Health Physics Elective Courses: & 9 & 3 \\
Elective Courses: & 9 & 6 \\
Thesis: & 0 & 9 \\
Total: & 30 & 30
\end{tabular}

\begin{tabular}{ll}
\multicolumn{2}{l}{ Required Courses } \\
HP 6403 & Radiological Health I \\
HP 6405 & Radiological Health II \\
HP 6601 & Industrial Hygiene \\
HP 6757 & Radiation Detection \\
& \\
Health Physics Elective Courses \\
HP 6416 & Applied Radiological Health Laboratory \\
HP 6506 & Operational Health Physics \\
HP 6755 & Radiological Assessment and Waste Management \\
HP 6756 & Radiation Physics \\
HP 6758 & Numerical Methods \\
HP 8803 & Special Topics in Health Physics
\end{tabular}

Because of the two-week delay for homework assignments and exams, distance learning students graduate in the term following that of their last completed course.

\section{Pros and Cons of Distance Delivery of the MSHP}

The distance learning MSHP program offers many benefits, both to Georgia Tech and to the students enrolled in the program. For Georgia Tech, one of the benefits is financial. Distance Learning students pay higher tuition fees per credit hour, yet create no additional "cost" to the university in terms of overhead costs or graduate student funding (i.e. GRA, GTA). A benefit to the NRE/HP program is the promotion of the Georgia Tech academic program by distance learning students to their colleagues. This word-of-mouth advertising leads to continued awareness of Georgia Tech's NRE and HP programs, as well as maintaining enrollment. 
The benefits to the distance learning students are manifold, including the ability to complete an advanced degree without leaving a satisfying/stable job, job advancement through professional development, tuition reimbursement offered by many employers, and the flexibility to integrate academic pursuits with personal and professional commitments. Campus students also benefit from the program; a copy of each taped lecture is kept on reserve in the Georgia Tech library during the semester and the courses are broadcast over the campus network. Registered students may checkout the videos should they miss a lecture due to illness or simply wish to review the material covered in class. Should a schedule conflict exist, campus students may enroll for a class through the CDL.

Unfortunately, there are also some negatives associated with the distance learning MSHP program. For Georgia Tech, this includes the lower retention rate inevitable with students possessing a number of interests competing for their time and attention. This leads to a need for constant recruitment of new students for the program. To the student, the time required to complete the degree may seem daunting. For a student taking two courses per semester, it will typically take three to four years to complete the degree requirements. In addition, the student has little direct interaction with faculty and other students. However, because of the maturity level of the typical distance learning student, this does not seem to adversely affect academic performance.

There is a cost associated with the convenience of taking courses as a distance learning student. The current enrollment fee is $\$ 530$ per credit hour, which includes tuition and the cost for shipping the course materials to the student. The student is responsible for return shipment of the video tapes, faxing exams/homework, and purchasing the textbook. For unsupported campus students, in-state tuition is $\$ 125$ per credit hour and out-of-state tuition is $\$ 501$ per credit hour. In addition, there are fees of $\$ 401$ per semester. Whether the cost of distance delivery presents a pro or con depends largely on whether one's employer provides tuition reimbursement.

\section{Statistics}

Steady enrollment in the distance learning MSHP program at Georgia Tech has helped to maintain the strength of Tech's health physics program during a period of decreasing enrollment in nuclear engineering and health physics programs nationwide. Since 1994, 159 students have been enrolled in the program. Seventy-three of these students were registered in the various professional development options, while eighty-six students were taking classes towards a degree under the registered graduate option. Table 1 compares the annual fall enrollments of video students with those for on-campus students.

The students in the distance learning MSHP program are drawn from across the country as shown in Figure 1. A significant number of students come from five states: Georgia (14), South Carolina (14), Maryland (12), New York (10), and Pennsylvania (10). Students are drawn from all segments of the health physics world, including government agencies, military, national labs, industry, utilities, hospitals, and consultants.

Proceedings of the 2001 American Society for Engineering Education Annual Conference \& Exposition Copyright (C) 2001, American Society for Engineering Education 
Measuring the retention rates of distance learning students is complicated by a variety of factors. The first of these is that records of this type are simply not maintained. The Center for Distance Learning maintains information on courses registered for and graduation dates. Unfortunately, if a distance learning student is not enrolled for a semester or two, no effort is made to determine if he/she has dropped from the program or is merely taking a break for job or personal reasons. Retention of video students is estimated to be approximately $60 \%$ for all degree programs offered by the Center for Distance Learning. For MSHP students, retention is higher, possibly as large as $75 \%$. This can be attributed to the professional advantages associated with an MSHP degree, including reducing the years of professional experience required to obtain certification by the American Board of Health Physics. In contrast, the retention rate of MSHP students on campus is approximately $92 \%$.

Since 1994, fifty-three distance learning students have completed the MSHP degree; fifty-nine campus students have graduated with the MSHP. Table 2 compares the annual number of video vs. campus MSHP graduates. Lower graduation rates among distance learning students can be attributed to a number of factors, including the longer time period required to complete course requirements and employment changes (new responsibilities, increased travel, new employer, etc.).

Comparing the grade point averages of distance learning students with campus students reveals that there is little
Table 1: Comparison of Enrollments

\begin{tabular}{ccc}
\hline Term & $\begin{array}{c}\text { Video } \\
\text { Enrollment }\end{array}$ & $\begin{array}{c}\text { Campus } \\
\text { Enrollment }\end{array}$ \\
\hline Fall 1994 & 61 & 73 \\
Fall 1995 & 53 & 54 \\
Fall 1996 & 59 & 47 \\
Fall 1997 & 23 & 37 \\
Fall 1998 & 28 & 39 \\
Fall 1999 & 18 & 23 \\
Fall 2000 & 16 & 12 \\
\hline
\end{tabular}

Includes MSHP and MSNE students
Figure 1: Distance Learning Enrollment by State

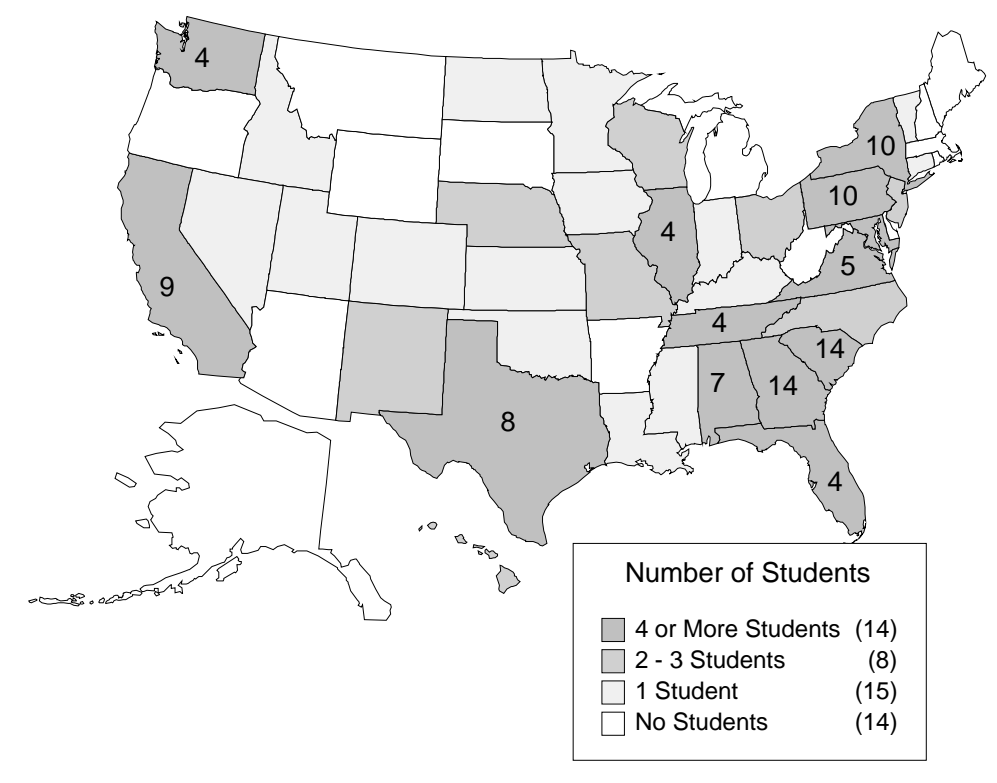

Proceedings of the 2001 American Society for Engineering Education Annual Conference \& Exposition Copyright (C) 2001, American Society for Engineering Education 
difference in academic achievement among students. The GPAs of MSHP students graduating between September 1993 and June 1999 averaged 3.45 for campus students and 3.51 for video students. The GPA data provided by the registrar encompassed thirty-five campus and eighteen distance learning MSHP graduates during the stated time interval.

\section{Conclusion}

The distance learning MSHP program at Georgia Tech has proven to be a valuable offering to practicing health physicists in industry and government. It allows for both professional development and the opportunity to complete a graduate degree without having to sacrifice employment or personal commitments. While providing a valuable service to the health physics community, it also benefits the university by maintaining the strength and reputation of Tech's NRE/HP programs.
Table 2: MSHP Degrees Awarded

\begin{tabular}{cccc}
\hline $\begin{array}{c}\text { Academic } \\
\text { Year }\end{array}$ & $\begin{array}{c}\text { Video } \\
\text { MSHP }\end{array}$ & $\begin{array}{c}\text { Campus } \\
\text { MSHP }\end{array}$ & $\begin{array}{c}\text { Total } \\
\text { Degrees }\end{array}$ \\
\hline $93-94$ & 12 & 16 & 28 \\
$94-95$ & 5 & 17 & 22 \\
$95-96$ & 10 & 4 & 14 \\
$96-97$ & 9 & 7 & 16 \\
$97-98$ & 7 & 5 & 12 \\
$98-99$ & 8 & 7 & 15 \\
$99-00$ & 2 & 3 & 5 \\
\hline TOTAL & 53 & 59 & 112 \\
\hline
\end{tabular}

\section{HEATHER J. GEPFORD}

Heather Gepford is a doctoral student at Georgia Institute of Technology. She received a B.S. in physics and math from Kansas State University and an M.S.E. in nuclear engineering from The University of Texas at Austin. Before returning to graduate school to obtain a Ph.D. in health physics, she worked as a Sr. Project Engineer for TN Technologies in Round Rock, TX and as a Health Physicist for Radiation Detection Company in Sunnyvale, CA.

NOLAN E. HERTEL

Nolan Hertel is a Professor of Nuclear and Radiological Engineering and Health Physics in the Woodruff School of Mechanical Engineering at Georgia Institute of Technology. He also serves as the Director of the Neely Nuclear Research Center. Dr. Hertel had been teaching nuclear engineering and health physics for 22 years. 